\title{
Evolutionary patchwork of an insecticidal toxin shared between plant-associated pseudomonads and the insect pathogens Photorhabdus and Xenorhabdus
}

\author{
Beat Ruffner ${ }^{1}$, Maria Péchy-Tarr², Monica Höfte ${ }^{3}$, Guido Bloemberg ${ }^{4}$, Jürg Grunder ${ }^{5}$, Christoph Keel ${ }^{2 *}$
} and Monika Maurhofer ${ }^{1 *}$

\begin{abstract}
Background: Root-colonizing fluorescent pseudomonads are known for their excellent abilities to protect plants against soil-borne fungal pathogens. Some of these bacteria produce an insecticidal toxin (Fit) suggesting that they may exploit insect hosts as a secondary niche. However, the ecological relevance of insect toxicity and the mechanisms driving the evolution of toxin production remain puzzling.

Results: Screening a large collection of plant-associated pseudomonads for insecticidal activity and presence of the Fit toxin revealed that Fit is highly indicative of insecticidal activity and predicts that Pseudomonas protegens and P. chlororaphis are exclusive Fit producers. A comparative evolutionary analysis of Fit toxin-producing Pseudomonas including the insect-pathogenic bacteria Photorhabdus and Xenorhadus, which produce the Fit related Mcf toxin, showed that fit genes are part of a dynamic genomic region with substantial presence/absence polymorphism and local variation in GC base composition. The patchy distribution and phylogenetic incongruence of fit genes indicate that the Fit cluster evolved via horizontal transfer, followed by functional integration of vertically transmitted genes, generating a unique Pseudomonas-specific insect toxin cluster.
\end{abstract}

Conclusions: Our findings suggest that multiple independent evolutionary events led to formation of at least three versions of the Mcf/Fit toxin highlighting the dynamic nature of insect toxin evolution.

Keywords: Pseudomonas, Photorhabdus and Xenorhabdus, Insecticidal activity, Toxin evolution

\section{Background}

Bacteria belonging to the Pseudomonas fluorescens group $[1,2]$ provide a compelling example of ecological and bacterial lifestyle diversity reflected by the vast range of environmental habitats they occupy. This group encloses plant-beneficial symbionts, environmental saprophytes and clinical strains of opportunistic human pathogens [3-5]. Within the $P$. fluorescens group, root-colonizing pseudomonads are well known for their ability to promote plant growth and to protect plants against soilborne pathogens

\footnotetext{
*Correspondence: christoph.keel@unil.ch; monika.maurhofer@usys.ethz.ch ${ }^{2}$ Department of Fundamental Microbiology, University of Lausanne, Biophore Building, CH-1015 Lausanne, Switzerland

'Pathology, Institute of Integrative Biology, ETH Zurich, Universitätstrasse 2, $\mathrm{CH}-8092$ Zurich, Switzerland

Full list of author information is available at the end of the article
}

through a set of diverse and functionally complementary mechanisms. The capacity to suppress fungal diseases has largely been attributed to the production of secondary metabolites with cytotoxic and antimicrobial activity, in particular 2,4-diacetylphloroglucinol (DAPG), phenazines, pyoluteorin, pyrrolnitrin, hydrogen cyanide, and lipopeptides $[4,6]$.

Extensive knowledge has been gathered over the last years on plant disease suppression and plant growth promotion. Surprisingly, it has become only recently apparent that specific strains of plant-associated pseudomonads are able to infect and kill insects [7-12]. These observations invoke that particular strains may function as insect pathogens and switch between insect hosts and the plant environment. Insecticidal activity in 
environmental pseudomonads was, with the exception of Pseudomonas entomophila, a pathogen of Drosophila [13-15], so far only rarely demonstrated. Initially, an insect toxin was discovered in silico when the genome of Pseudomonas protegens Pf-5 (previously called $P$. fluorescens Pf-5) became available [16]. Subsequent molecular and mutational characterization revealed that oral and injectable insecticidal activity is linked to the Fit ( $P$. fluorescens insecticidal toxin) gene, which was described and characterized for the first time in $P$. protegens strains $\mathrm{CHA} 0$ and Pf-5 [7, 12]. Injection of Fit expressing E. coli is sufficient to induce strong melanization and rapid death of the tobacco hornworm Manduca sexta and larvae of the greater wax moth Galleria mellonella [7]. Fit toxin knock-out mutants of CHA0 have attenuated virulence, both when injected into G. mellonella or fed to African cotton leafworm Spodoptera littoralis [7, 12]. The Fit gene cluster consists of eight genes (fitABCDEFGH) with functions in toxin export, insect toxicity and regulation (Fig. 1). The Fit insect toxin gene fitD is flanked upstream by fitABC and downstream by fitE encoding components of a type I secretion system. The products of the fitFGH genes regulate toxin production $[7,8,10,11]$. FitF is a sensor histidine kinase - response regulator hybrid, detecting the insect environment and activating insecticidal toxin expression via FitH and FitG [11].

Genome sequencing revealed that certain strains of Pseudomonas chlororaphis also harbour the complete fit gene cluster (Fig. 1) [17]. Contribution of the Fit toxin to the oral insecticidal activity has been demonstrated for P. chlororaphis PCL1391 against S. littoralis [12].

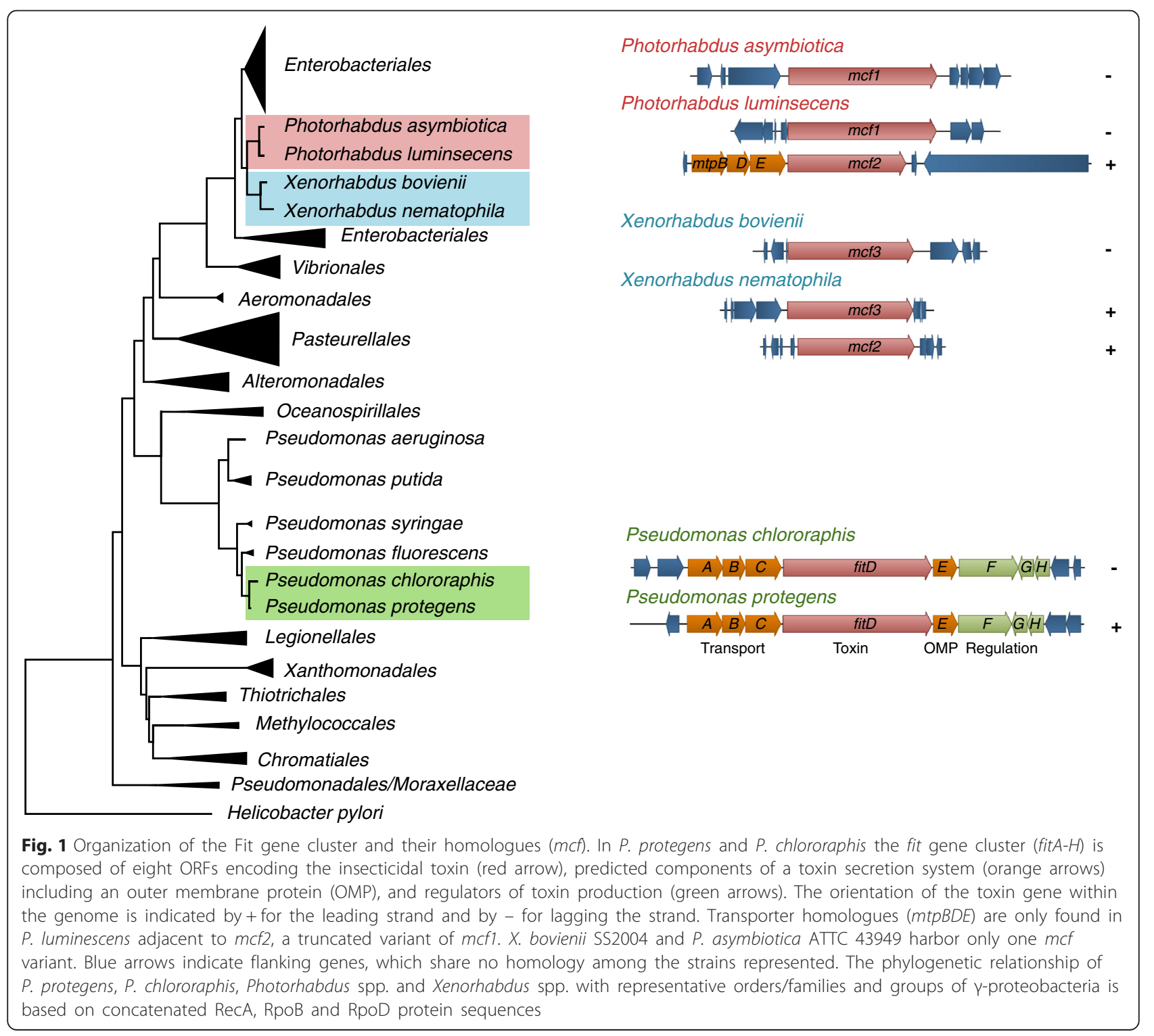


The Fit insect toxin shares $73 \%$ identity with the makes caterpillars floppy insecticidal toxin Mcf1 and $67 \%$ with Mcf2, both produced by Photorhabdus luminescens, a bacterial symbiont of entomopathogenic nematodes [7, 18, 20]. Mcf-like toxins are also found in Photorhabdus asymbiotica, Xenorhabdus nemtophila and Xenorhabdus bovienii (Fig. 1) [18-21]. The Mcf1 toxin causes rapid disruption of the insect midgut epithelium and hemocytes triggered by a $\mathrm{BH}$-3-like apoptosis control domain $[18,22]$. Injection of purified Mcf1 in Drosophila embryos leads to a freezing phenotype of hemocytes, due to a rearrangement of the actin cytoskeleton [23]. While Mcf toxins are essentially studied in the Photorhabdus lineage the evolutionary basis for the homology between Fit and Mcf toxins has remained unclear.

Here, we conducted comparative sequence analysis in combination with virulence assays to yield a better understanding of insect pathogenicity in plant-associated pseudomonads. In order to study Fit/Mcf toxin evolution we have sequenced seven Pseudomonas genomes to retrieve the entire gene cluster. We analyzed evolutionary footprints of the Pseudomonas Fit gene cluster and the related Mcf genes of the insect pathogenic Photorhabdus and Xenorhabdus bacteria and found patterns of recent horizontal transfer.

This study suggests that the Fit toxin is restricted to a particular group of plant-colonizing pseudomonads consisting of $P$. protegens and $P$. chlororaphis. We show that the presence of the fit toxin gene strongly correlates with high insect toxicity and thus is a suitable molecular marker for potent insecticidal activity in fluorescent pseudomonads. Absence of the Fit toxin gene in closely related pseudomonads and the genomic context suggest that fit genes have evolved in part via exchange of genetic material from phylogenetically distantly related bacteria. The acquisition of the Fit toxin within pseudomonads may represent an ancient event in the evolution towards a distinct ecotype of insect-associated pseudomonads. Our analysis further indicates substantial rearrangements within Photorhabdus/Xenorhabdus lineage of these insecticidal toxins thereby extending and diversifying the existing toxin repertoire of these entomopathogens.

\section{Results and discussion}

Survey of diverse pseudomonads predicts $P$. protegens and $P$. chlororaphis as exclusive Fit producers within plant-colonizing pseudomonads

We investigated the occurrence of Fit toxin production in plant-associated pseudomonads and tested whether insect toxin production is linked to specific ecological and molecular characteristics. We screened a large worldwide collection of Pseudomonas isolates (103) from soil and roots of different plant species using generic primers directed against the Fit toxin gene fitD (Additional file 1: Table S1). In addition to the root-associated isolates, we tested 15 strains representing the major phylogenetic groups within the genus Pseudomonas and strains isolated from different environments including invertebrates such as cyclops, earthworms or isopods for the presence of the fitD gene. The phylogenetic relationship of the investigated strains based on concatenated sequences of the three housekeeping genes rec $A, r p o B$ and rpoD is shown in Fig. 2a.

PCR amplification and sequencing showed the presence of the toxin in 29 strains (Fig. 2a, Additional file 1: Table S1). In addition, PCR results were verified using Southern blotting on a subset of isolates (data not shown). We detected the Fit toxin gene only in two phylogenetic subgroups within the $P$. fluorescens group (grouping according to $[1,2])$. The first subgroup comprises fluorescent pseudomonads that produce both the antifungal metabolites DAPG and PLT [24, 25] including our model strain P. protegens CHA0 [26]. As the second group of Fit toxin gene carriers, we were able to identify members of the $P$. chlororaphis subgroup (Fig. 2a). We included in addition to $P$. protegens $\mathrm{CHAO}$ and Pf- 5 the sequenced strains P. chlororaphis GP72 [27], Pseudomonas aureofaciens 30-84 [17] and Pseudomonas CMR12a (unpublished data) all harboring the Fit gene cluster. CMR12a is placed next to the group of DAPG and PLT producers, although CMR12a is phylogenetically clearly distinct from these strains (Fig. 2a) and does not produce the two antifungal compounds $[28,29]$.

\section{Insecticidal activity strongly correlates with the presence of the Fit toxin gene}

We aimed to test if insecticidal activity is restricted to a particular group of pseudomonads and whether presence of the Fit toxin is predictive of insecticidal activity. To this end, the insecticidal activity of selected strains from phylogenetically and functionally diverse subgroups within the P. fluorescens group (Fig. 2a) was tested using a previously established assay with larvae of the greater wax moth Galleria mellonella [7]. Tested strains included representatives of different phylogenetic subgroups of DAPG-producers and some DAPG non-producing strains (Fig. 2a). Injection assays with Galleria larvae demonstrated that Pseudomonas strains harboring the fitD toxin gene display potent insecticidal activity while the naturally fitD-negative sister group fails to induce significant mortality (Fig. 2b). Since insecticidal activity is restricted to a particular group and substantial toxicity is retained in fitD knock-out mutants [7], insecticidal activity is likely driven by other shared traits. We have previously shown that the fit toxin gene significantly contributes to the insecticidal activity, but requires additional 
A

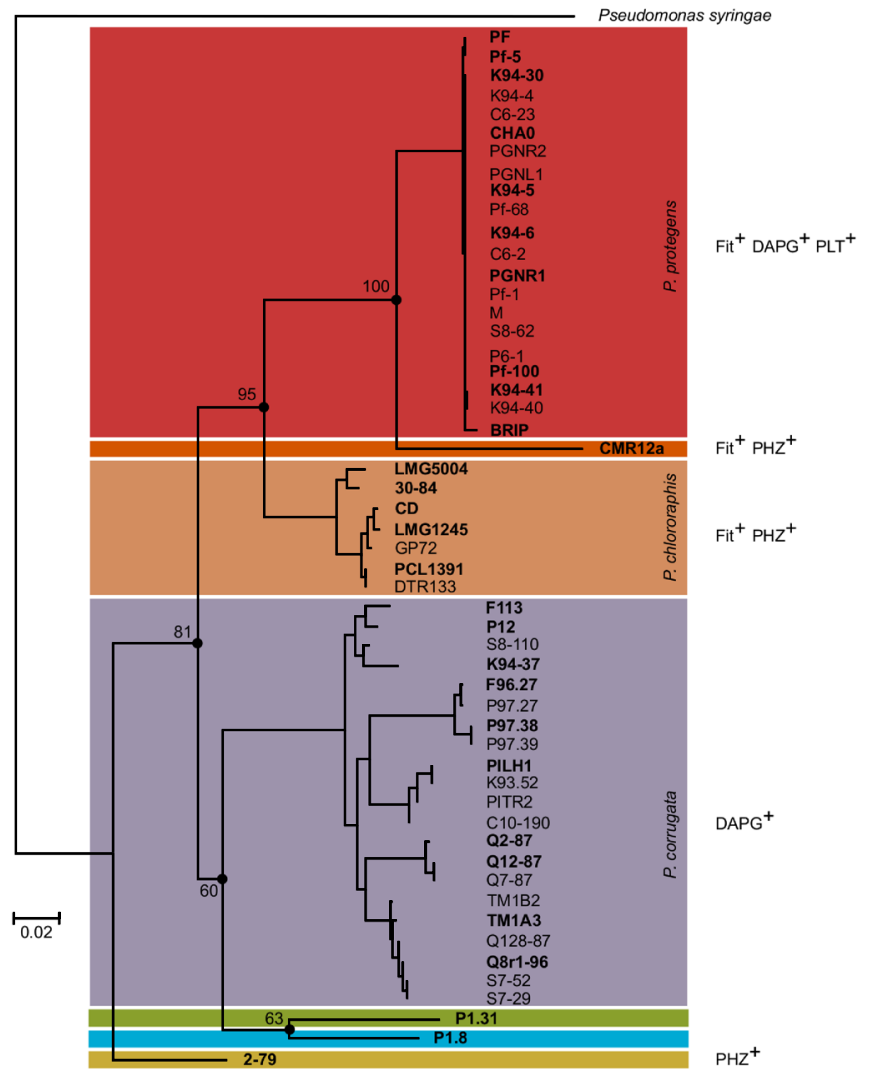

B

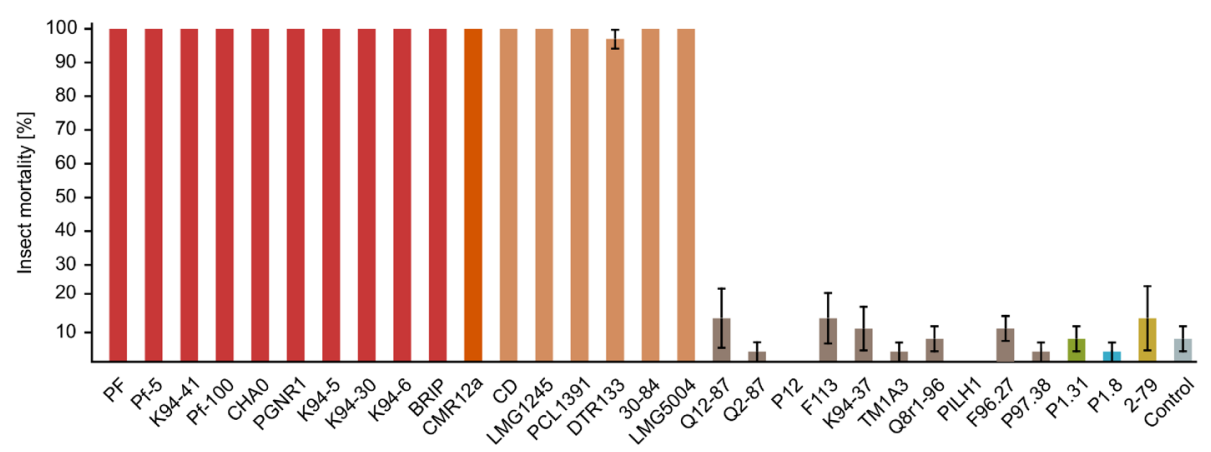

Fig. 2 Insecticidal activity correlates with presence of the fitD gene. (a) The Phylogenetic relationship amongst 29 closely related plant-associated Fit ${ }^{+}$ and $24 \mathrm{Fit}^{-}$pseudomonads is based on the three concatenated housekeeping genes recA, rpoB and rpoD consisting of a total of 1469 nucleotide sites with Pseudomonas syringae as outgroup. Strains/subgroups harboring the Fit toxin gene and major antifungal compounds produced by the pseudomonads are indicated: DAPG, 2-4-diacetylphloroglucinol; PHZ, phenazines; and PLT, pyoluteorin. The evolutionary history was inferred using PhyML 3.0. Bootstrap values are based on 100 replicates and indicated for major nodes indicated by circles. Only the P. protegens and $P$. chlororaphis subgroups harbor the Fit toxin gene. The $P$. corrugata subgroup containing DAPG producers is indicated as defined by Mulet [1, 2]. (b) Insect mortality of G. mellonella larvae four days after injection of $4 \times 10^{4}$ cells of 17 Fit producing and 13 non-producing Pseudomonas strains. Tested strains are shown in bold in (A). Each strain was tested on a total of 30 larvae (five replicate plates with six larvae per plate). Bars show average of insect mortality for each strain. Error bars show standard error of the mean. The experiment was repeated with similar results (Additional file 2: Table S2). Fit ${ }^{+}$strains were significantly different from $\mathrm{Fit}^{-}$based on Wilcoxon rank sum test grouped by $\mathrm{Fit}^{+}$and $\mathrm{Fit}^{-}$strains $(P<0.05)$

factors for full activity that are regulated by the GacS/GacA system [11, 12]. Nevertheless, the Fit toxin gene seems to be predictive of insecticidal activity in root-colonizing fluorescent pseudomonads.

\section{The Fit gene cluster is located in a dynamic genomic} region

To characterize the Fit gene cluster among Pseudomonas spp. we generated high quality assemblies of seven 
toxin-producing strains (i.e., $P$. protegens $\mathrm{CHA0}$, BRIP, PGNR1, K94.41, and PF and P. chlororaphis PCL1391 and CD of which) covering the entire Fit toxin cluster and flanking regions. The complete genome sequence of $\mathrm{CHA} 0$ has recently been published [30]. Sequences containing the fit genes were aligned to the reference sequence of strains Pf-5 and 30-84 $[16,17]$. All seven strains contain the complete fit toxin cluster (fitABCDEFGH). The Fit gene cluster in the genome of Pf-5 is embedded in a large genomic region, with features indicative of horizontal acquisition, such as phage-related proteins and unusual nucleotide composition (Fig. 3a) [17]. The fit cluster in P. chlororaphis strains 30-84 and O6 is located in a different part of the genome within a 24-28 gene insertion (Fig. 3b) [17]. We were able to define a $165-\mathrm{kb}$ region of the Pf-5 genome flanked by steep residual $\mathrm{G}+\mathrm{C}$ content clines (Fig. 3a). Abrupt changes in the residual cumulative $\mathrm{G}+\mathrm{C}$ content curve may point to foreign genetic elements, such as horizontally acquired genes, phagederived elements or other mobile elements [31]. The corresponding genomic region in strain PF is highly similar to that of Pf-5 and in both strains the region is delimited at the 5 '-end by a type I restriction modification system and by phage-related proteins at the 3 '-end. Interestingly, comparisons of the respective regions among the six $P$. protegens strains show a high level of insertion-deletion polymorphism. In particular, the type I restriction-modification system is present in strains Pf-5, PF, K94.41 and BRIP, but absent in PGNR1 and CHA0 (Fig. 3a). The gene cluster encoding the rhizoxin biosynthesis is unique to $\mathrm{Pf}-5$ and PF as well as the phage-related proteins [32]. A polysaccharide synthesis gene cluster ( $p e l)$ is common to all $P$. protegens strains and located upstream of the Fit cluster. In Pseudomonas aeruginosa, Pel is one of at least three secreted extracellular polysaccharides implicated in biofilm formation [33].

The genomic context of the fit genes in $P$. protegens differs from that in P. chlororaphis (Fig. 3b). Using the residual cumulative $\mathrm{G}+\mathrm{C}$ content approach a region of $45 \mathrm{~kb}$ composed of 34 ORFs was defined in P. chlororaphis strain 30-84. Similar to $P$. protegens, there is substantial presence/absence polymorphism. In strains $C D$ and PCL1391, adjacent to a gene encoding a putative membrane-associated transporter upstream of fitA, a nine-ORF gene cluster involved in ribose uptake and utilization is located, which was assumed to be unique to the $P$. chlororaphis subgroup of the $P$. fluorescens group [17].

\section{Fit gene cluster: a phylogenetic patchwork}

Since only strains of $P$. protegens and $P$. chlororaphis were identified as carriers of the Fit toxin, we were interested in the evolutionary origin of this gene cluster. High similarities between protein sequences in distantly related species, patchy distribution or phylogenetic incongruence indicate potential horizontal transmission of a gene [34]. BLASTP searches, revealed a very distinct phylogenetic distribution of Fit components. Consistent with horizontal transmission, most of the Fit components (except FitE and FitG) have significant best hits outside the Pseudomonas (Additional file 2: Table S2). Initial sequence analysis of the Fit toxin from $P$. protegens strain CHA0 revealed $73 \%$ sequence identity over the entire protein to the insecticidal protein Mcfl of $P$. luminescens strain TT01 [7]. Mcf2 of TT01 shares $67 \%$ identity with FitD (Additional file 3: Figure S1). Mcf1 is also present in P. asymbiotica ATCC 4394, but this bacterium appears to have lost Mcf2 [20]. Similarly, X. bovienii SS2004 and X. nematophila ATCC 19061, both sister species of Photorhabdus, carry an Mcf variant, which we call here Mcf3 with $69 \%$, respectively, $65 \%$ overall identity to FitD and highest identity ( $79 \%$, respectively $76 \%$ ) in a 900 amino acid N-terminal overlap. Mcf3 is also present in Photorhabdus temperata [35]. Within the genus Xenorhabdus Mcf2 is only found in X. nematophila ATCC 19061 with an overall identity of $64 \%$ to FitD. Mcf-like proteins are also found in other $\gamma$-Proteobacteria including Vibrio and Providencia spp. Distantly related Fit-like genes (27-28 \% identity) [7, 17], (Additional file 2: Table S2) with a predicted TcdA/TcdB pore-forming domain can also be found in $P$. brassicacearum and diverse Fit-negative P. fluorescens strains, but none of the representative strains of this group tested in our virulence tests (i.e., P12, Q8r196, Q2-87, Q12-87, belonging to the P. corrugata subgroup) caused significant insect mortality (Fig. 2b). Interestingly, FitA, FitB and FitC with predicted function in toxin secretion [7] revealed highest similarities (69 \%, $65 \%$ and $73 \%$ amino acid identity) with the RTX toxin transporter encoded by the genomic region adjacent to the Mcf2 insect toxin gene of $P$. luminescens (Additional file 2: Table S2, Fig. 4). Similar genes, however, are absent in proximity of $m c f 1$ and $m c f 3$ as well as of $m c f 2$ of Xenorhabdus (Figs. 1 and 4). The only fit components showing closest identity to the genus Pseudomonas are FitE $(62 \%$ identity to $P$. brassicacearum) and the regulatory protein FitG (45\% identity to P. fluorescens and Serratia sp.). The other proteins involved in regulation of toxin expression (FitF and FitH) show closest identity to Dechloromonas aromatica (41\%) and Vibrio sp. (54\%), respectively. The three regulatory proteins FitF, FitG and FitH are absent in Photorhabdus/Xenorhabdus, suggesting a Pseudomonas-specific regulation of Fit. However, we cannot rule out an earlier existence of the whole cluster also in Photorhabdus/Xenorhabdus but that transport 
A

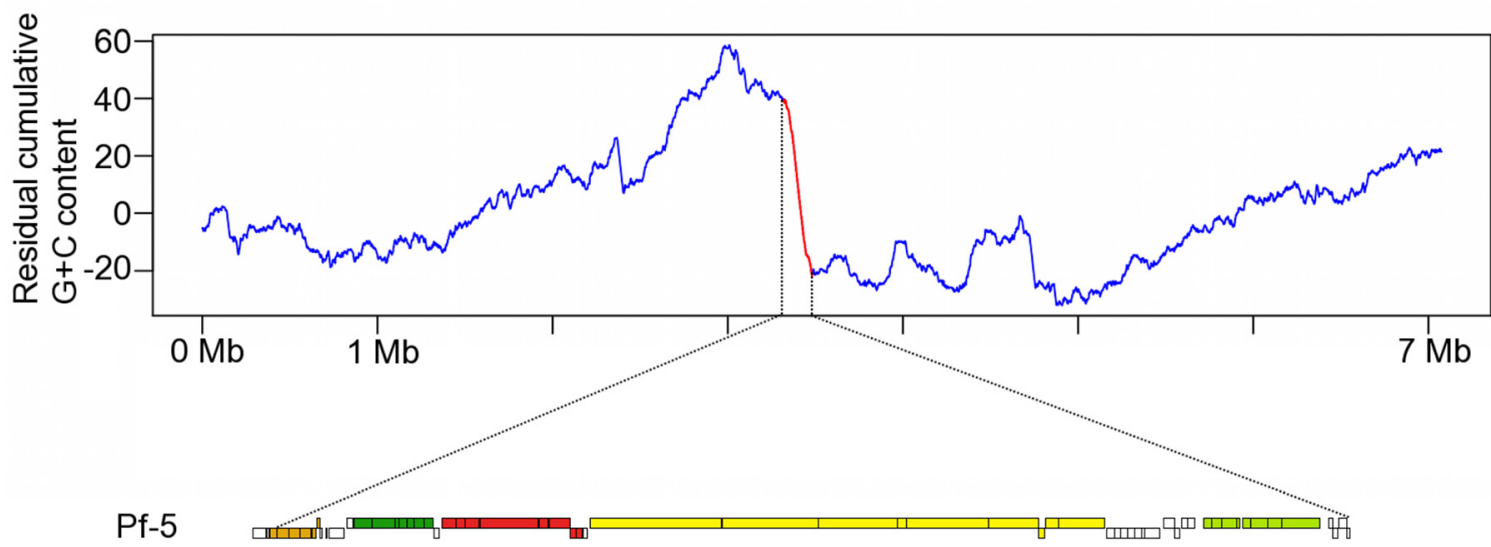

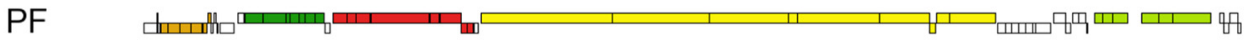

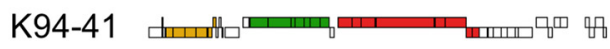

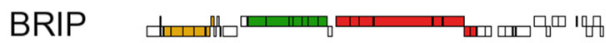

PGNR1 म

- Polysaccharide biogenesis (Pel cluster)

- Fit cluster

Rhizoxin biosynthesis

CHAO dín

B

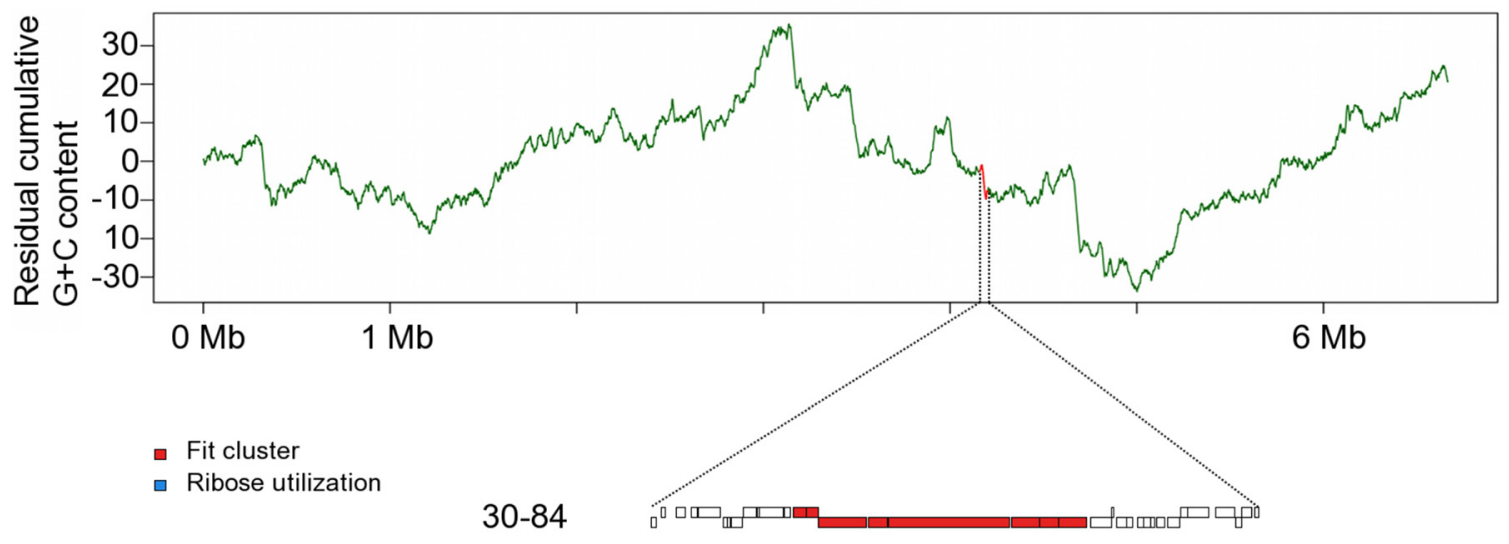

CD

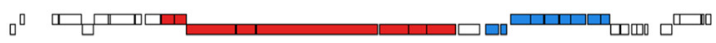

Fig. 3 (See legend on next page.)

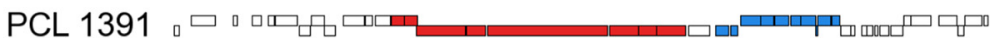


(See figure on previous page.)

Fig. 3 Comparison of the Fit cluster harbouring region. Within P. protegens (a) and P. chlororaphis (b) subgroups indicates a high degree of absence/presence polymorphism. The genomic region was defined based on residual cumulative $\mathrm{G}+\mathrm{C}$ content analysis of $P$. protegens strain Pf-5 and P. chlororaphis strain 30-84, where steep slopes indicate local variations in $\mathrm{G}+\mathrm{C}$ content indicative of foreign elements. Compared with Pf-5 and PF, the genomic region of strains K94.41, BRIP, PGNR1 and CHA0 is notably downsized

and regulatory genes were subsequently lost. Mcf2 in Photorhabudus luminescens, for example is still flanked by the three transport genes.

The patchy phylogenetic distribution of Fit/Mcf toxins and the absence of the toxin in closely related Pseudomonas species e. g members of the $P$. corrugata subgroup strongly suggest that the Fit cluster evolved in part via horizontal acquisition, followed by functional integration of vertically transmitted genes, making up a unique virulence cluster within the subclade of $P$. chlororaphis and $P$. protegens.

\section{Mosaic composition of Fit/Mcf toxin variants}

Aligning the genomic regions of FitD and Mcf variants encoding sequences reveals a mosaic like structure of toxin-encoding parts and associated components. The fitD-encoding region of $P$. protegens and $P$. chlororaphis shows extraordinarily high similarity over the entire gene (69-75 \%) to $m c f 1$ of P. luminescens and P. asymbiotica. However, immediately adjacent flanking regions drop below the threshold of alignable sequences set at $50 \%$ similarity in a $100 \mathrm{bp}$ window (Fig. 4). Short stretches sharing over $70 \%$ nucleotide similarity outside the

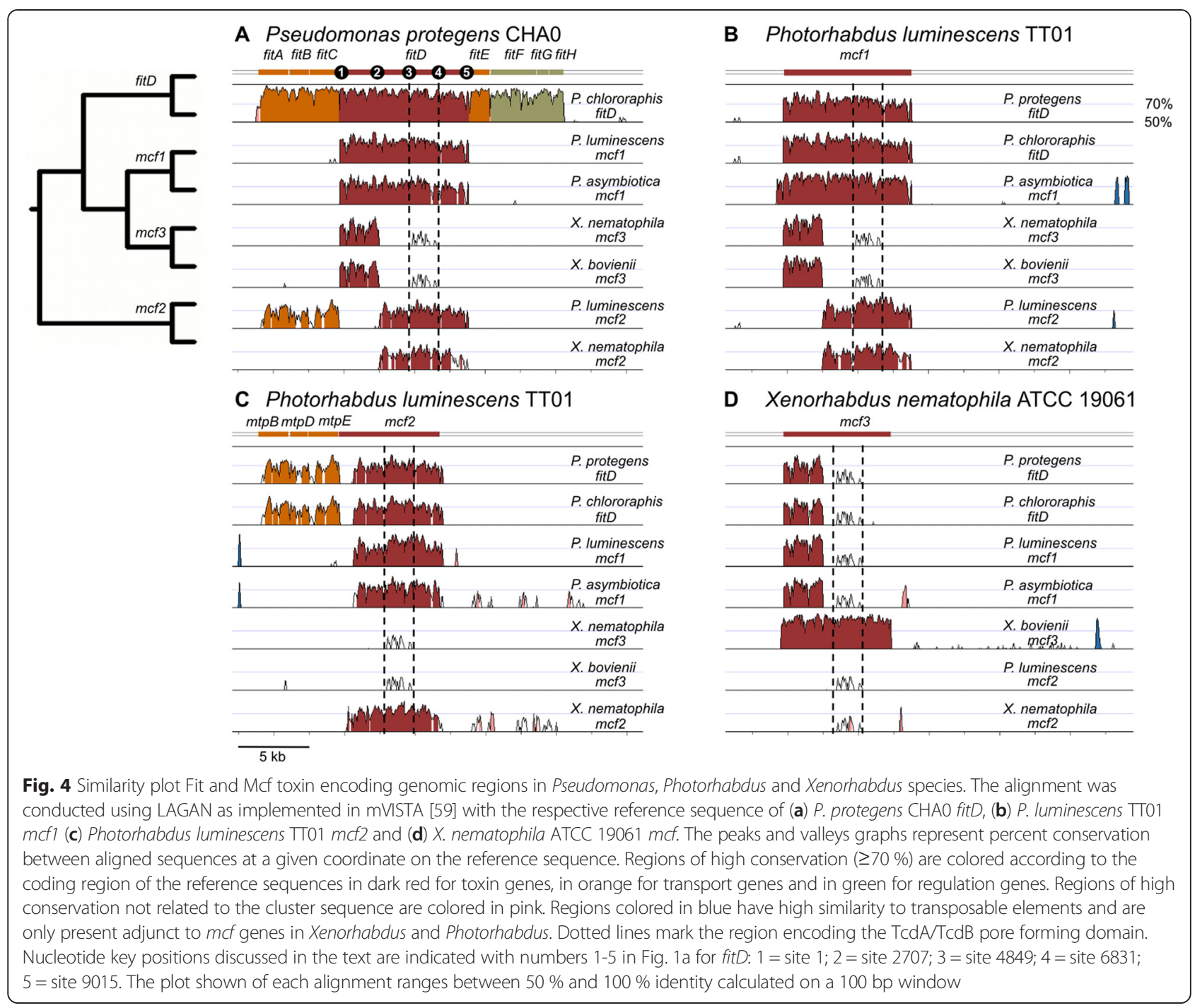


designated toxin encoding regions indicated by sharp peaks in the similarity plots among $P$. luminescens, $P$. asymbiotica as well as between $P$. luminescens genes $m c f 1$ and $m c f 2$ include fragments with predicted association to transposable elements (Fig. 4).

Within the Photorhabdus/Xenorhabdus lineage three variants of Mcf toxins can be determined based on their sequential make up: Mcf1, Mcf2 and Mcf3. While insect toxicity has been demonstrated at several levels for Mcf1 and Mcf2 from Photorhabdus [18, 19, 23], and FitD from Pseudomonas 2013 [7, 12], the functionality of Xenorhabdus Mcf toxins remains to be tested, in particular of Mcf3 the most distinct toxin variant discussed in this paper.

The VISTA alignment presented in Fig. 4 shows the mosaic-like structure of Mcf variants. While fitD and $m c f 1$ share high homology over the entire nucleotide sequence, $m c f 3$ in the Xenorhabdus lineage and also present in $P$. temperata shares only the $5^{\prime}$ '-end (Position 1-2, Fig. 4) with fitD/mcf1 (Figs. 4 and 5a). Including $m c f 2$ in the alignment, it becomes apparent, that it is exactly this stretch at the mcf3 5 ' -end with high homology to fitD/ $m c f 1$, which is entirely missing in $m c f 2$ (Figs. 4 and 5). BLAST searches revealed that the sequence towards the 3 '-end (Position 2-5, Fig. 4) of the Xenorhabdus mcf3 shows for most of this stretch (position 2-3 and position 4-5, Fig. 4) no similarity to the other $m c f / f i t D$ variants and did not allow to identify a putative origin. The rapid drop from $>70 \%$ similarity to $40 \%$ between position 1 and 2 (Fig. 4) coincide with a breakpoint indicated by SBP (Single Breakpoint Recombination) analysis. In the middle of this stretch there is a part (position 34, Fig. 4) which again shows a low similarity (50-70 \% at the nucleotide level, Fig. 4) to the TcdA/TcdB pore forming domain of fit, $m c f 1$ and $m c f 2$. Thus, all investigated toxin variants encode a TcdA/TcdB poreforming domain in this region, however, based on amino acid and nucleotide comparison, it seems that these pore-forming domains originate from at least two different ancestors (Fig. 4). A phylogenetic tree conducted on the TcdA/TcdB pore forming domain indeed suggests a monophyletic origin for the pore-

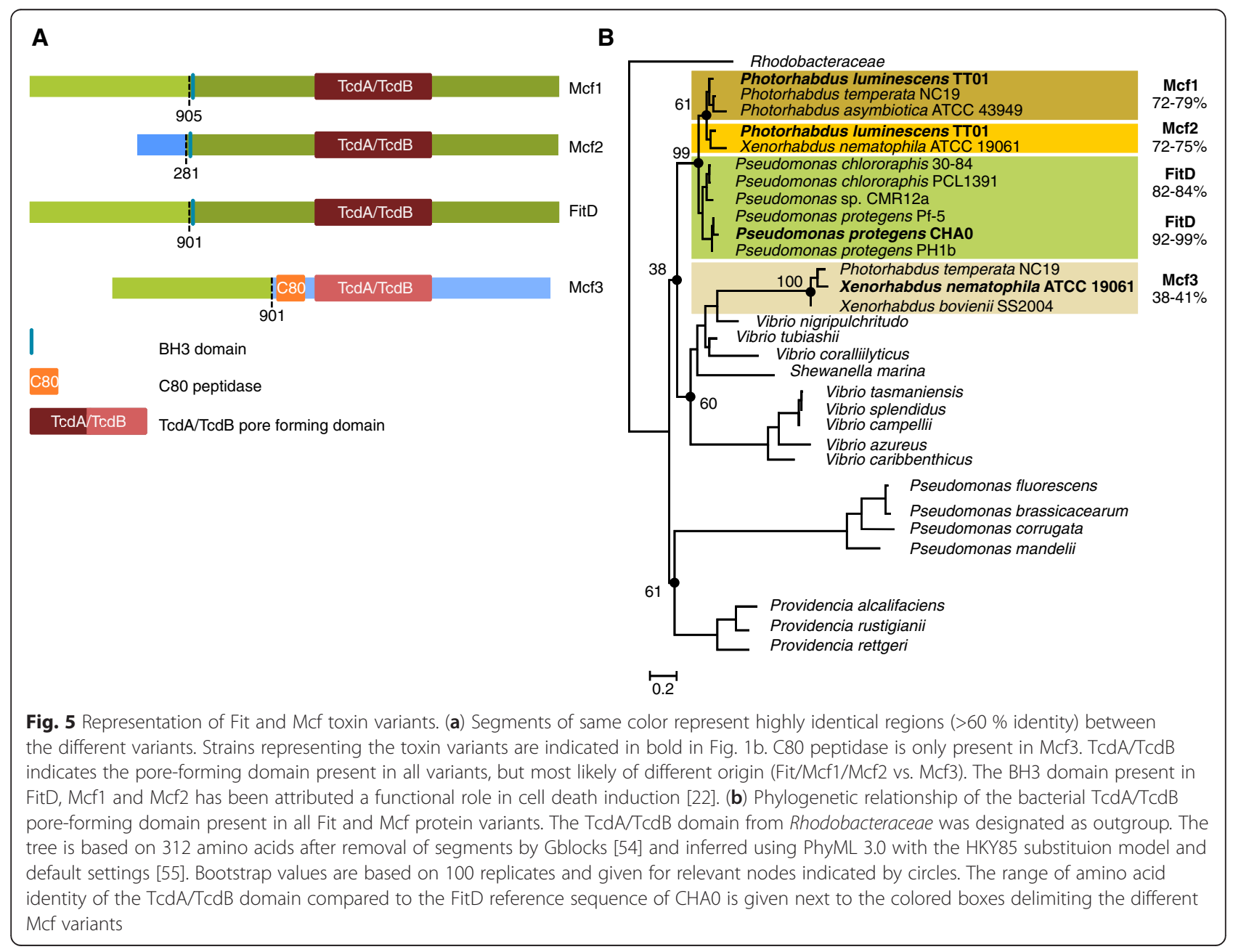


forming domain of FitD/Mcf1 and Mcf2, but a different origin for that of Mcf3 found in Xenorhabdus and P. temperata (Fig. 5b).

The mosaic composition of the different fit/mcf variants, the presence of transposable elements and the patchy phylogenetic distribution of the toxin could indicate a highly mobile nature of this gene. An unusual GC content of a gene/segment, is a further indication of horizontal acquisition, assuming that donor and recipient have a sufficiently high degree of base composition differences [36,37]. While the average GC content of $P$. luminescens TT01 (43.9\%) and X. nematophila ATCC 19061 (45.3 \%) genomes is low, Pseudomonas spp. have high overall GC content (P. protegens Pf-5: $64.0 \%$; $P$. chlororaphis 30-84: 63.8\%). Comparing the GC content of fitD and $m c f 1$ to the respective average of all genes within the same strain, the $m c f 1$ gene in P. luminescens displays an unusual high GC content $(56.2 \%$ vs. 43.9 \%), whereas the fitD gene in Pseudomonas is within the range of the average GC content of the genome (e.g., Pf-5: $65.2 \%$ vs. $64.0 \%$ ) (Table 1). In addition, only $0.3 \%$ of $P$. luminescens genes display an equal or higher GC content than $m c f 1$ and $r t x D$ and $r t x B$ (homologous to fitA and fitB in P. luminescens adjunct to $m c f 2$ ) (data not shown). Interestingly, all investigated $m c f$ variants of Xenorhabdus spp. do not show such obvious abnormality (50 \% vs. $45 \%)$ (Table 1).

The unusual nucleotide composition of $m c f 1$ and $m c f 2$ in Photorhabdus contradicts the hypothesis that pseudomonads acquired the insect toxin from entomopathogenic Photorhabdus. However, horizontal acquisition of $m c f$ in Photorhabdus from an unknown ancestral vector is very likely. In P. chlororaphis and P. protegens the nucleotide composition of the fit genes does not differ from the average of the whole genome (Table 1). Therefore, one might speculate that pseudomonads have acquired the toxin earlier than Photorhabdus and the fit codon usage has already adapted to the Pseudomonas background or that pseudomonads have acquired the toxin from a bacterium displaying a similar nucleotide composition.

$m c f$ toxin genes are not only shuffled around in bacteria. A recent study by Ambrose [38] indicates that a $m c f$-like gene of the fungal grass endosymbiont Epichloë poae, which is sufficient to confer a lethal phenotype when expressed in E. coli cells and injected into the black cutworms Agrotis ipsilon, has derived from a

Table 1 GC content of fitD and mcf genes

\begin{tabular}{|c|c|c|c|c|c|c|}
\hline Strain & Gene & Position & Strand & Length (bp) & GC content $(\%)$ & GC content genome $(\%)$ \\
\hline \multicolumn{7}{|c|}{ Pseudomons protegens } \\
\hline Pf-5 & fit $D$ & 3350746.3359757 & + & 9012 & 65.2 & 64.0 \\
\hline \multirow[t]{4}{*}{$\mathrm{CHAO}$} & fitD & $3362990 . .3371995$ & + & 9006 & 65.1 & 63.4 \\
\hline & fitA & $3357171 . .3359312$ & + & 2142 & 65.4 & \\
\hline & fitB & $3359309 . .3360697$ & + & 1389 & 65.7 & \\
\hline & fitC & $3360700 . .3362859$ & + & 2160 & 66.9 & \\
\hline \multicolumn{7}{|c|}{ Pseudomonas chlororaphis } \\
\hline 3084 & fit $D$ & $4176228 . .4185206$ & + & 8979 & 66.1 & 62.9 \\
\hline \multicolumn{7}{|c|}{ Photorhabdus luminescens } \\
\hline \multirow[t]{5}{*}{ Тт01 } & mcfl & $4832190 . .4841195$ & - & 8994 & 56.2 & 43.9 \\
\hline & $m c f 2$ & $3670273 . .3677427$ & + & 7155 & 52.0 & \\
\hline & Plu3125 & $3664486 . .3666606$ & + & 2121 & 54.8 & \\
\hline & Plu3126 & 3666606.3667994 & + & 1389 & 55.8 & \\
\hline & Plu3127 & $3667994 . .3670153$ & + & 2160 & 57.3 & \\
\hline \multicolumn{7}{|c|}{ Photorhabdus asymbiotica } \\
\hline ATCC 43949 & mcfl & $3962994 . .3971975$ & + & 5982 & 54.4 & 42.2 \\
\hline \multicolumn{7}{|c|}{ Xenorhabdus nematophila } \\
\hline \multirow[t]{2}{*}{ ATCC 19061} & $m c f$ & $2205090 . .2212682$ & + & 7593 & 50.7 & 45.3 \\
\hline & $m c f 2$ & $1917776 . .1924951$ & + & 7176 & 50.2 & \\
\hline \multicolumn{7}{|c|}{ Xenorhabdus bovienii } \\
\hline SS-2004 & mcf & $2380592 . .2388193$ & - & 7602 & 50.6 & 45.0 \\
\hline
\end{tabular}

${ }^{\mathrm{a}}$ Encode predicted transporters and are homologous to fitA, fit $B$ and fitC respectively 
single lineage-specific horizontal transfer of bacterial origin [38].

\section{Conclusions}

The plant environment was assumed to be the dominant niche of $P$. fluorescens group bacteria, but it becomes apparent that some members, notably $P$. protegens and $P$. chlororaphis, which harbor the Fit insect toxin, are capable of colonizing and killing insects [7-12,17]. The present comparative analysis study provides a better understanding of the processes driving the evolution of insect pathogenicity in environmental pseudomonads. The Fit virulence cassette seems to be ubiquitous for $P$. protegens and $P$. chlororaphis and is encoded in dynamic portions of the $P$. protegens and $P$. chlororaphis genomes with substantial absence/presence polymorphism, phage-related genes and an unusual base composition, while in the Photorhabuds/Xenorhabdus lineage transposable elements are located in proximity of the Mcf gene. It would therefore appear that evolutionary processes including the acquisition of insecticidal elements, sequence rearrangements (as demonstrated in this study) and protein adaptation through domain shuffling (as demonstrated by Kupferschmied [11]) allowed plantassociated pseudomonads to adapt to a new ecological niche. In line with the genomic arguments of horizontal acquisition are the patchy distributed fit components that share highest homology with bacteria outside the Pseudomonadaceae family. Our data show that a specific group of plant-colonizing pseudomonads have evolved a unique virulence gene cluster through diverse evolutionary processes, which contributed to extend their existing repertoire of antifungal and antipredator activities with insecticidal activity. Frequent mobilization and recombination is possibly favored by the common niche of insect hosts shared between these particular Pseudomonas, Photorhabdus and Xenorhabdus bacteria, and may provide a selective advantage by the diversification of the toxin gene repertoire.

\section{Methods}

\section{Bacterial strains}

Bacterial strains used in the present study are summarized in Additional file 1: Table S1. For the screening, we relied on a worldwide strain collection of Pseudomonas spp. isolated from the rhizosphere, roots and leaves of various plant species [24, 25, 39-41]. Strains belonging to the genus Photorhabdus and Xenorhabdus were originally isolated from entomopathogenic nematodes (Steinernema and Heterorhabditis species) sampled from diverse soils in Switzerland using Galleria mellonella larvae as baits [42]. Bacteria used in this study were cultured on King's medium B (KMB) agar plates, or in lysogeny broth (LB) at $27{ }^{\circ} \mathrm{C}$ [43-45]. Additional strains from environmental samples were isolated by plating serial dilutions on $\mathrm{KMB}$ supplemented with antibiotics at the following concentrations: chloramphenicol $13 \mu \mathrm{g} \mathrm{ml}^{-1}$, ampicillin $40 \mu \mathrm{g} \mathrm{ml}{ }^{-1}$ and cycloheximide $100 \mu \mathrm{g} \mathrm{ml}^{-1}$. For single gene amplification, DNA was obtained from overnight LB cultures diluted 1:500 with sterile distilled $\mathrm{H}_{2} \mathrm{O}$ and incubated for 10 min at $96^{\circ} \mathrm{C}$ to lyze bacterial cells.

\section{Insect toxicity assay}

Washed bacterial cells from overnight cultures in (LB) were suspended in $0.9 \%$ sterile $\mathrm{NaCl}$ solution and adjusted to an $\mathrm{OD}_{600}=0.01$. Aliquots of $5 \mu \mathrm{l}$, corresponding to an injection dose of $4 \times 10^{4}$ cells, were injected into the haemolymph of ultimate-instar G. mellonella larvae (Hebeisen Fishing, Zürich, Switzerland) using a Hamilton microsyringe with a 26-gauge needle [7]. Sterile $\mathrm{NaCl}$ solution served as control. Treated larvae were incubated in Greiner six-well plates at room temperature and scored as live or dead regularly over four days. For each bacterial strain, five replicate plates with six larvae per plate were prepared. The experiment was repeated twice with similar results. Mortality was defined as the inablity of larvae to react to poking. Significance between $\mathrm{Fit}^{+}$and $\mathrm{Fit}^{-}$pseudomonads was assessed based on Wilcoxon rank sum test $(\mathrm{P} \leq 0.05)$. For data analyses, $\mathrm{R}$ version 3.1 .1 was used [46].

\section{Taxon determination}

For the taxon determination of uncharacterized strains, a 455-bp $16 \mathrm{~s}$ rDNA fragment was amplified and sequenced using the universal primers $\mathrm{f} 933$ and r1387 [47]. For strains belonging to the genus Pseudomonas three housekeeping genes were used in addition, amplified and sequenced with primers recAf1, recAr1 for $r e c A$ (537 bp), rpoBf1, rpoBr1 for rpoB (508 bp) and rpoDf1, rpoDr1 for rpoD (695 bp) [24]. PCR reactions were conducted according to the standard protocol for use of Dream TAQ Polymerase (Fermentas GmbH, St. Leon-Rot, Germany). PCR products were electrophoreticaly separated on $1 \%$ agarose gels and purified using the Nucleo-Fast PCR purification kit (Macherey-Nagel). Sequencing was carried out using the BigDye ${ }^{\circ}$ Terminator v3.1 Cycle Sequencing Kit (Life Technologies Cooperation, Carlsbas, USA). Sequencing products were purified on Sephadex G-50 followed by capillary elctrophoresis separation using an ABI Hitachi 3130xl Prism Genetic Analyzer (Applied Biosystems). The obtained sequences were blasted against public available genomic sequences on the NCBI website.

\section{Sequencing of fit gene cluster and fitD/mcf1 fragments}

Pairs of primers for the amplification of fitD/mcf1 genes were designed based on the fitD sequences of P. protegens strains $\mathrm{CHA} 0$ and $\mathrm{Pf}-5$. Primer specificity 
was tested in silico using BLASTN against assemblies of whole genome shotgun sequences from the NCBI website. Primer pairs are fit1f 5-TGGCTTTTATGTCCAAG GAC-3', fit1r 5'-TGGTTGGCGAAGTACTGCTC-3' (position 2-962) and fit2f 5'-CTGACCACGTTCGACGCC GAGCAATG-3', -fit2r 5'-TAACGTCCCACCGCCTTGG CATCTTCG-3' (position 4828-5702) and allowed amplifiaction of $f i t D, m c f 3$ and $m c f 1$, but not $m c f 2$. The fit1f/fit1r primer pair was tested on a collection of Pseudomonas, Photorhabdus and Xenorhabdus spp. listed in Additional file 1: Table S1. Amplification with primers fit1f and fit1r yielded one single amplicon ranging from 914 to $980 \mathrm{bp}$ for $P$. protegens, $P$. chlororaphis, Photorhabdus and Xenorhabdus strains carrying the fitD, $m c f 3$ or $m c f 1$ insect toxin genes, respectively. For $P$. protegens and $P$. chlororaphis, a second fitD fragment was amplified and sequenced with primer pair fit2f/fit2r resulting in one single amplicon of $875 \mathrm{bp}$. PCR reactions and sequencing of the two fragments were conducted as described above for housekeeping genes.

Illumina sequencing was applied to retrieve the entire fit cluster and flanking genes of $P$. protegens strains $\mathrm{PF}$, K94.41, BRIP, PGNR1, and CHA0 and P. chlororaphis strains PCL1391 and CD. Genomic DNA was extracted from $10 \mathrm{ml} \mathrm{LB}$ overnight culture grown from a single colony using the DNeasy extraction kit (Qiagen). Sequence data consisted of 90-bp paired-end Illumina reads carried out on a 500-bp library. The short reads were assembled using SOAPdenovo version 1.05 [48]. Contigs that harbor the fit genes were identified by BLASTN searches and annoted on the RAST server [49]. The sequence obtained for $\mathrm{CHAO}$ is in accordance with the recently published genome of CHA0 (NCBI accession no. CP003190, [30].

Vista alignments shown in Fig. 4 were performed using mVISTA [50, 51] with LAGAN as alignment algorithm on $100 \mathrm{bp}$ window. The genomic region encoding either the Fit toxin for Pseudomonas species or the homologous Mcf toxin in Photorhabdus and Xenorhabdus (NC005126, NC012962, NC014228, NC013892) species were extracted using BioEdit (http://www.mbio.ncsu.edu/ BioEdit/bioedit.html) $25 \mathrm{~kb}$ downwards and $25 \mathrm{~kb}$ upwards from the starting codon of the toxin encoding gene $(f i t / m c f)$ and oriented according to the transcription direction of fitD from P. protegens CHA0.

\section{Phylogenetic analysis}

Public available gene sequences for housekeeping genes of previously characterized Pseudomonas and other $\gamma$-proteobacterial strains included in the phylogentic analyses were retrieved from GenBank (http:// ncbi.nlm.nih.gov/genbank) and added to our dataset. For the phylogenetic analysis shown in Fig. 2 sequences of the three housekeeping genes (recA, rpoB, rpoD) were concatenated into a single combined dataset using
BioEdit (http://www.mbio.ncsu.edu/BioEdit/bioedit.html). Sequence data sets were all aligned using MUSCLE [52] implemeted in MEGA5 [53] and alignment gaps and poorly aligned segements were removed with Gblocks [54] resulting in data sets of $1469 \mathrm{bp}$. Tree topologies based on nucleotide sequences (Fig. 2) were inferred using PhyML 3.0 with HKY85 substituion model and default settings [55]. The node supports were evaluated based on 100 bootstrap replicates.

The tree in Fig. 1 was inferred on concatenated whole protein sequences of RecA, RpoB and RpoD using the LG amino acid replacment matrix [56]. For the TcdA/tcdB phylogeny shown in Fig. 5, a BLASTP search was performed based on the amino acid domain sequence of $P$. luminescens of TT01 and the tree inferred as described above for protein sequences. The presence of the $T c d A / T c d B$ poreforming domain in this region was confirmed by SMART (http://smart.embl-heidelberg.de).

Single Breakpoint Recombination analysis on $m c f / f i t$ sequences were performed on the Datamonkey webserver (http://www.datamonkey.org).

\section{In silico detection of Fit components}

The amino acid sequences of fit genes of $P$. protegens CHAO [7] served as query for BLASTP searches against completed bacterial genomic sequences. BLAST searches are summarized in Additional file 3: Figure S1.

\section{Residual cummulative GC content}

GC content for fit genes was calculated using the seqinr package implented in $R$ [57]. Identification of the genomic region carrying the fit cluster was defined on local variations of $\mathrm{G}+\mathrm{C}$ content of the $P$. protegens $\mathrm{Pf}-5$ and $P$. chlororaphis 30-84 genomes. GC content of genomes as listed in Table 1 are retrieved from the NCBI genome database. The residual cumulative GC content analyses were conducted according to a GC profile approach [31] described previously by [58]. First, the $G+C$ content is calculated in a 1-kb sliding window with 20-bp steps before the residual cumulative $\mathrm{G}+\mathrm{C}$ content is presented as bidimensional graph on which chromosome positions on the horizontal axis are plotted versus the residues on the vertical axis. A DNA stretch enriched or depleted in G's and C's is indicated by a steep slope on the graphs in Fig. 3.

\section{Availability of supporting data}

Sequence data supporting the results of this article are available in LabArchives (DOI:10.6070/H47M05X, http://dx.doi.org/10.6070/H47M05X0) 


\section{Additional files}

\section{Additional file 1: Table S1. Bacterial strains used in this study} [60-106].

Additional file 2: Table S2. BLASTp analysis of $P$. protegens $\mathrm{CHAO}$

Fit components against completed bacterial whole genome sequences.

Additional file 3: Figure S1. Insecticidal activity correlates with presence of the fitD gene.

\section{Competing interests}

The authors declare that they have no competing interests.

\section{Authors' contributions}

$\mathrm{BR}, \mathrm{CK}$ and MM were involved in the study design. BR and MPT performed the experiment and analysed the results. BR, CK and MM participated in the data analyses and in developing the first draft through the final submitted version of the manuscript. MH, JG and GB contributed reagents and materials. All authors read and approved the final manuscript.

\section{Acknowledgments}

This work was supported by the Swiss National Foundation for Scientific Research (Projects 3100A0-105881 and 31003A-138248), the Swiss State Secretariat for Education and Research (Project C07.0026, COST action 862) and the Fund for Scientific Research Flanders (FWO grant 3G000210 to MH). The Genetic Diversity Center at ETH Zurich (GDC) provided sequencing facilities. The authors are particularly grateful to Alina Gradolf and Daniel Croll for valuable discussions, and Pascale Flury for technical assistance.

\section{Author details}

${ }^{1}$ Pathology, Institute of Integrative Biology, ETH Zurich, Universitätstrasse 2, $\mathrm{CH}-8092$ Zurich, Switzerland. '2Department of Fundamental Microbiology, University of Lausanne, Biophore Building, CH-1015 Lausanne, Switzerland. ${ }^{3}$ Laboratory of Phytopathology, Department of Crop Protection, Ghent University, Ghent, Belgium. ${ }^{4}$ Institute of Medical Microbiology, University of Zurich, Zurich, Switzerland. ${ }^{5}$ Natural Resources Sciences, University of Applied Sciences ZHAW, Wädenswil, Switzerland.

\section{Received: 12 February 2015 Accepted: 9 July 2015}

Published online: 16 August 2015

\section{References}

1. Mulet M, Lalucat J, García-Valdés E. DNA sequence-based analysis of the Pseudomonas species. Environ Microbiol. 2010;12:1513-30

2. Mulet M, Gomila M, Scotta C, Sánchez D, Lalucat J, García-Valdés E. Concordance between whole-cellmatrix-assisted laser-desorption/ionization time-of-flight mass spectrometry and multilocus sequence analysis approaches in species discrimination within the genus Pseudomonas. Syst Appl Microbiol. 2012;35:455-64

3. Compeau G, Al-Achi BJ, Platsouka E, Levy SB. Survival of rifampin-resistant mutants of Pseudomonas fluorescens and Pseudomonas putida in soil systems. Appl Environ Microbiol. 1988;54:2432-8.

4. Haas D, Défago G. Biological control of soil-borne pathogens by fluorescent pseudomonads. Nat Rev Microbiol. 2005:3:307-19.

5. Rossignol G, Sperandio D, Guerillon J, Duclairoir Poc C, Soum-Soutera E, Orange N. Phenotypic variation in the Pseudomonas fluorescens clinica strain MFN1032. Res Microbiol. 2009;160:337-44.

6. Haas D, Keel C. Regulation of antibiotic production in root-colonizing Peudomonas spp. and relevance for biological control of plant disease. Annu Rev Phytopathol. 2003;41:117-53.

7. Péchy-Tarr M, Bruck DJ, Maurhofer M, Fischer E, Vogne C, Henkels MD, et al. Molecular analysis of a novel gene cluster encoding an insect toxin in plant-associated strains of Pseudomonas fluorescens. Environ Microbiol. 2008;10:2368-86

8. Péchy-Tarr M, Borel N, Kupferschmied P, Turner V, Binggeli O, Radovanovic D, et al. Control and host-dependent activation of insect toxin expression in a root-associated biocontrol pseudomonad. Environ Microbiol. 2013:15:736-50.
9. Olcott MH, Henkels MD, Rosen $\mathrm{KL}$, Walker FL, Sneh B, Loper JE, et al. Lethality and developmental delay in Drosophila melanogaster larvae after ingestion of selected Pseudomonas fluorescens strains. PLOS ONE. 2010;5:e12504.

10. Kupferschmied P, Maurhofer M, Keel C. Promise for plant pest control: root-associated pseudomonads with insecticidal activities. Frontiers in Plant Science. 2013;4:article 287.

11. Kupferschmied P, Péchy-Tarr M, Imperiali N, Maurhofer M, Keel C. Domain shuffling in a sensor protein contributed to the evolution of insect pathogenicity in plant-beneficial Pseudomonas protegens. PLoS Pathog. 2014;10:e1003964

12. Ruffner B, Péchy-Tarr M, Ryffel F, Hoegger P, Obrist C, Rindlisbacher A, et al. Oral insecticidal activity of plant-associated pseudomonads. Environ Microbiol. 2013;15:751-63.

13. Liehl P, Blight M, Vodovar N, Boccard F, Lemaitre B. Prevalence of local immune response against oral infection in a Drosophila/Pseudomonas infection model. PLoS Pathog. 2006;2:e56.

14. Opota O, Vallet-Gély I, Vincentelli R, Kellenberger C, lacovache I, Gonzalez MR, et al. Monalysin, a novel ß-pore-forming toxin from the Drosophila pathogen Pseudomonas entomophila, contributes to host intestinal damage and lethality. PLoS Pathog. 2011:7:e1002259.

15. Vodovar N, Vinals M, Liehl P, Basset A, Degrouard J, Spellman P, et al. Drosophila host defense after oral infection by an entomopathogenic Pseudomonas species. Proc Natl Acad Sci U S A. 2005;102:11414-9.

16. Paulsen IT, Press CM, Ravel J, Kobayashi DY, Myers GS, Mavrodi DV, et al. Complete genome sequence of the plant commensal Pseudomonas fluorescens Pf-5. Nat Biotechnol. 2005;23:873-8.

17. Loper JE, Hassan KA, Mavrodi DV, Davis 2nd EW, Lim CK, Shaffer BT, et al. Comparative genomics of plant-associated Pseudomonas spp.: insights into diversity and inheritance of traits involved in multitrophic interactions. PLoS Genet. 2012;8:e1002784.

18. Daborn PJ, Waterfield N, Silva CP, Au CPY, Sharma S, Ffrench-Constant RH. A single Photorhabdus gene, makes caterpillars floppy (mcf), allows Escherichia coli to persist within and kill insects. Proc Natl Acad Sci U S A. 2002;99:10742-7

19. Dowling AJ, Daborn PJ, Waterfield NR. The insecticidal toxin Makes caterpillars floppy (Mcf) promotes apoptosis in mammalian cells. Cell Microbiol. 2004:6:345-53.

20. Wilkinson P, Waterfield NR, Crossman L, Corton C, Sanchez-Contreras M, Vlisidou I, et al. Comparative genomics of the emerging human pathogen Photorhabdus asymbiotica with the insect pathogen Photorhabdus luminescens. BMC Genomics. 2009;10:302.

21. Sugar DR, Murfin KE, Chaston JM, Andersen AW, Richards GR, deLéon L, et al. Phenotypic variation and host interactions of Xenorhabdus bovienii SS-2004, the entomopathogenic symbiont of Steinernema jollieti nematodes. Environ Microbiol. 2012;14:924-39.

22. Dowling AJ, Waterfield NR, Hares MC, Le Goff G, Streuli CH, FfrenchConstant $\mathrm{RH}$. The Mcf1 toxin induces apoptosis via the mitochondrial pathway and apoptosis is attenuated by mutation of the $\mathrm{BH} 3$-like domain. Cell Microbiol. 2007;9:2470-84.

23. Vlisidou I, Dowling AJ, Evans IR, Waterfield N, Ffrench-Constant RH, Wood W. Drosophila embryos as model systems for monitoring bacterial infection in real time. PLoS Pathog. 2009;5:e1000518.

24. Frapolli M, Défago G, Moënne-Loccoz Y. Multilocus sequence analysis of biocontrol fluorescent Pseudomonas spp. producing the antifungal compound 2,4-diacetylphloroglucinol. Environ Microbiol. 2007:9:1939-55

25. Keel C, Weller DM, Natsch A, Défago G, Cook RJ, Thomashow LS. Conservation of the 2,4-diacetylphloroglucinol biosynthesis locus among fluorescent Pseudomonas strains from diverse geographic locations. App Environ Microbiol. 1996;62:552-63.

26. Ramette A, Frapolli M, Fischer-Le Saux M, Gruffaz C, Meyer JM, Défago G, et al. Pseudomonas protegens sp. nov., widespread plant-protecting bacteria producing the biocontrol compounds 2,4-diacetylphloroglucinol and pyoluteorin. Syst Appl Microbiol. 2011;34:180-8.

27. Shen X, Chen M, Hu H, Wang W, Peng H, Xu P, et al. Genome sequence of Pseudomonas chlororaphis GP72, a root-colonizing biocontrol strain. J Bacteriol. 2012;194:1269-70.

28. Mavrodi DV, Peever TL, Mavrodi OV, Parejko JA, Raaijmakers JM, Lemanceau P, et al. Diversity and evolution of the phenazine biosynthesis pathway. Appl Environ Microbiol. 2010;76:866-79. 
29. Perneel M, Heyrman J, Adiobo A, De Maeyer K, Raaijmakers JM, De Vos P, et al. Characterization of CMR5C and CMR12a, novel fluorescent Pseudomonas strains from the cocoyam rhizosphere with biocontrol activity. J Appl Microbiol. 2007;103:1007-20.

30. Jousset A, Schuldes J, Keel C, Maurhofer M, Daniel R, Scheu S, et al. Full-genome sequence of the plant growth-promoting bacterium Pseudomonas protegens CHA0. Genome Announc. 2014;2:e00322-14.

31. Zhang $R$, Zhang CT. A systematic method to identify genomic islands and its applications in analyzing the genomes of Corynebacterium glutamicum and Vibrio vulnificus CMCP6 chromosome I. Bioinformatics. 2004;20:612-22.

32. Takeuchi K, Noda N, Someya N. Complete genome sequence of the biocontrol strain Pseudomonas protegens Cab57 discovered in Japan reveals strain-specific diversity of this species. PLoS One. 2014;9:e93683.

33. Franklin MJ, Nivens DE, Weadge JT, Howell PL. Biosynthesis of the Pseudomonas aeruginosa extracellular polysaccharides, alginate, pel, and psl. Front Microbiol. 2011;2:167.

34. Silva JC, Loreto EL, Clark JB. Factors that affect the horizontal transfer of transposable elements. Curr Issues in Mol Biol. 2004;6:57-71.

35. Ullah I, Jang EK, Kim MS, Shin JH, Park GS, Khan AR, et al. Identification and Characterization of the insecticidal toxin "makes caterpillars floppy" in Photorhabdus temperata using a cosmid library. Toxins. 2014;6:2024-40.

36. Ochman H, Lawrence JG, Groisman EA. Lateral gene transfer and the nature of bacterial innovation. Nature. 2000;405:299-304.

37. Gogarten JP, Townsend JP. Horizontal gene transfer, genome innovation and evolution. Nat Rev Microbiol. 2005:3:679-87.

38. Ambrose KV, Koppenhöfer AM, Belanger FC. Horizontal gene transfer of a bacterial insect toxin gene into the Epichloë fungal symbionts of grasses. Sci Rep. 2014;4:5562.

39. Ramette A, Frapolli M, Défago G, Moënne-Loccoz Y. Phylogeny of HCN synthase-encoding hcnBC genes in biocontrol fluorescent pseudomonads and its relationship with host plant species and HCN synthesis ability. Mol Plant Microbe Interact. 2003;16:525-35.

40. Ramette A, Loccoz YM. Genetic diversity and biocontrol potential fluorescent pseudomonads producing phloroglucinols and hydrogen cyanide from Swiss soils naturally suppressive or conducive to Thielaviopsis basicola-mediated black root rot of tobacco. FEMS Microbiol Ecol. 2006;55:369-81.

41. Wang C, Ramette A. Cosmopolitan distribution of phID-containing dicotyledonous crop-associated biocontrol pseudomonads of worldwide origin. FEMS Microbiol Ecol. 2001;37:105-16.

42. Fan X, Hominick WM. Efficiency of the Galleria (wax moth) baiting technique for recovering infective stages of entomopathogenic rhabditids (Steinernematidae and Heterorhabditidae) from sand and soil. Revue Nématol. 1991;14:381-87.

43. Bertani G. Studies on lysogenesis. I. The mode of phage liberation by lysogenic Escherichia coli. J Bacteriol. 1951;62:293-300.

44. King EO, Ward MK, Raney DE. Two simple media for the demonstration of pyocyanin and fluorescin. J Lab Clin Med. 1954;44:301-7.

45. Schnider-Keel U, Seematter A, Maurhofer M, Blumer C, Duffy B, Gigot-Bonnefoy C, et al. Autoinduction of 2,4-diacetylphloroglucinol biosynthesis in the biocontrol agent Pseudomonas fluorescens $\mathrm{CHAO}$ and repression by the bacterial metabolites salicylate and pyoluteorin. J Bacteriol. 2000;182:1215-25.

46. Ihaka R, Gentleman R. R: A language for data analysis and graphics. J Comput Graph Stat. 1996:5:299-314.

47. Iwamoto T, Tani K, Nakamura K, Suzuki Y, Kitagawa M, Eguchi M, et al. Monitoring impact of in situ biostimulation treatment on groundwate bacterial community by DGGE. FEMS Microbiol Ecol. 2000;32:129-41.

48. Li R, Zhu H, Ruan J, Qian W, Fang X, Shi Z, et al. De novo assembly of human genomes with massively parallel short read sequencing. Genome Res. 2010;20:265-72.

49. Aziz RK, Bartels D, Best AA, DeJongh M, Disz T, Edwards RA, et al. The RAST Server: rapid annotations using subsystems technology. BMC Genomics. 2008;9:75.

50. Mayor C, Brudno M, Schwartz JR, Poliakov A, Rubin EM, Frazer KA, et al. VISTA: visualizing global DNA sequence alignments of arbitrary length. Bioinformatics. 2000;16:1046-47.

51. Frazer KA, Pachter L, Poliakov A, Rubin EM, Dubchak I. VISTA: computational tools for comparative genomics. Nucleic Acids Res. 2004;32:273-79.

52. Edgar RC. MUSCLE: a multiple sequence alignment method with reduced time and space complexity. BMC Bioinformatics. 2004;5:113.
53. Tamura K, Peterson D, Peterson N, Stecher G. MEGA5: molecular evolutionary genetics analysis using maximum likelihood, evolutionary distance, and maximum parsimony methods. Mol Biol Evol. 2011; 28:2731-39.

54. Castresana J. Selection of conserved blocks from multiple alignments for their use in phylogenetic analysis. Mol Biol Evol. 2000;17:540-52.

55. Guindon S, Dufayard JF, Lefort V, Anisimova M, Hordijk W, Gascuel O. New algorithms and methods to estimate maximum-likelihood phylogenies: assessing the performance of PhyML 3.0. Syst Biol. 2010;59:307-21.

56. Le SQ, Gascuel O. Accounting for solvent accessibility and secondary structure in protein phylogenetics is clearly beneficial. Syst Biol. 2010;59:277-87.

57. Charif D, Lobry JR. SeqinR 1.0-2: a contributed package to the R project for statistical computing devoted to biological sequences retrieval and analysis. In: Bastolla U, Porto M, Roman HE, editors. Structural approaches to sequence evolution. New York: Springer Verlag; 2007. p. 207-32.

58. Greub G, Collyn F, Guy L, Roten CA. A genomic island present along the bacterial chromosome of the Parachlamydiaceae UWE25, an obligate amoebal endosymbiont, encodes a potentially functional F-like conjugative DNA transfer system. BMC Microbiol. 2004;4:48.

59. Brudno M, Do CB, Cooper GM, Kim MF, Davydov E. NISC Comparative Sequencing Program, et al. LAGAN and Multi-LAGAN: efficient tools for large-scale multiple alignment of genomic DNA. Genome Res. 2003; 13:721-31.

60. Lopez-Reyes L, Soto-Urzua L, Mascarua-Esparza J, Caballero-Mellado J. Antibiotic resistance and $\beta$-lactamse activity in Azospirillum. Soil Biol Biochem. 1989;21:651-5.

61. Dobbelaere S, Croonenborghs A, Thys A, Ptacek D. Responses of agronomically important crops to inoculation with Azospirillum. Aust J Plant Physiol. 2001;28:871-9.

62. Fages J, Mulard D. Isolement de bactéries rhizospériques et effet de leur inoculation en pot chez Zea mays. Agronomie. 1988;8:309-14.

63. Gobbin D, Rezzonico F, Gessler C. Quantification of the biocontrol agent Pseudomonas fluorescens Pf153 in soil using a quantitative competitive PCR assay unaffected by variability in cell lysis- and DNA-extraction efficiency. Soil Biol Biochem. 2007:39:1609-19.

64. Pemberton JM, Corney B, Don RH. Evolution and spread of pesticide degrading ability among soil microorganisms. In: Timmis KN, Puhler A, editors. Plasmids of medical, environmental and commercial importance. Amsterdam: Elsevier; 1979. p. 287-99.

65. Smits THM, Rezzonico F, Kamber T, Blom J, Goesmann A, Frey JE, et al. Complete genome sequence of the fire blight pathogen Erwinia amylovora CFBP 1430 and comparison to other Erwinia spp. Mol Plant Microbe Interact. 2010;23:384-93.

66. McGowan SJ, Sebaihia M, O'Leary S, Hardie KR, Williams P, Stewart GS, et al. Analysis of the carbapenem gene cluster of Erwinia carotovora: definition of the antibiotic biosynthetic genes and evidence for a novel beta-lactam resistance mechanism. Mol Microbiol. 1997;26:545-56.

67. Molina L, Constantinescu F, Michel L, Reimmann C, Duffy B, Défago G. Degradation of pathogen quorum-sensing molecules by soil bacteria: $a$ preventive and curative biological control mechanism. FEMS Microbiol Ecol. 2003;45:71-81.

68. Blattner FR. The complete genome sequence of Escherichia coli K-12. Science. 1997;277:1453-62.

69. Fischer-Le Saux M, Viallard V, Brunel B, Normand P, Boemare NE. Polyphasic classification of the genus Photorhabdus and proposal of new taxa: $P$. luminescens subsp. luminescens subsp. nov., P. luminescens subsp. akhurstii subsp. nov., $P$. luminescens subsp. laumondii subsp. nov., $P$. temperata sp. nov., P. temperata subsp. temperata subsp. nov. and P. asymbiotica sp. nov. Int J Syst Bacteriol. 1999;4:1645-56.

70. Holloway BW. Genetic recombination in Pseudomonas aeruginosa. J Gen Microbiol. 1955;13:572-81.

71. Pierson LS, Thomashow LS. Cloning and heterologous expression of the phenazine biosynthetic locus from Pseudomonas aureofaciens 30-84. Mol Plant Microbe Interact. 1992;5:330-9.

72. Landa BB, Cachinero-Díaz JM, Lemanceau P, Jiménez-Díaz RM, Alabouvette C. Effect of fusaric acid and phytoanticipins on growth of rhizobacteria and Fusarium oxysporum. Can J Microbiol. 2002;48:971-85.

73. Chin-A-Woeng TF, Bloemberg GV, van der Bij AJ, van der Drift KMG, Schripsema J. Biocontrol by phenazine-1-carboxamide-producing Pseudomonas chlororaphis PCL1391 of tomato root rot caused by 
Fusarium oxysporum f. sp. radicis-lycopersici. Mol Plant Microbe Interact. 1998;13:1340-5.

74. Scarlett CM, Flechter JT, Roberts P, Lelliott RA. Tomato pith necrosis caused by Pseudomonas corrugata n. sp. Ann Appl Biol. 1978;88:105-14.

75. Weller DM, Cook RJ. Supression of Take-All of wheat by seed treatments with fluorescent pseudomonads. Phytopathology. 1983;73:463-9.

76. Fuchs J, Défago G. Protection of cucumber plants against black root rot caused by Phomopsis sclerotioides with rhizobacteria. IOBC/WPRS Bulletin. 1991;14:57-62.

77. Fenton AM, Stephens PM, Crowley J. Exploitation of gene(s) involved in 2 4-diacetylphloroglucinol biosynthesis to confer a new biocontrol capability to a Pseudomonas strain. Appl Environ Microbiol. 1992;58:3873-8.

78. Rezzonico F, Défago G, Moënne-Loccoz Y. Comparison of ATPaseencoding type III secretion system hrcN genes in biocontrol fluorescent Pseudomonads and in phytopathogenic proteobacteria. Appl Environ Microbiol. 2004;70:5119-31.

79. Voisard C, Keel C, Haas D, Défago G. Cyanide production by Pseudomonas fluorescens helps suppress black root rot of tobacco under gnotobiotic conditions. EMBO J. 1989:8:351-8.

80. Fuchs JG, Moënne-Loccoz $Y$. The laboratory medium used to grow biocontrol Pseudomonas sp. Pf153 influences its subsequent ability to protect cucumber from black root rot. Soil Biol Biochem. 2000;32:421-4.

81. Vincent MN, Harrison LA, Brackin JM, Kovacevich PA, Mukerji P, Weller DM, et al. Genetic analysis of the antifungal activity of a soilborne Pseudomonas aureofaciens strain. Appl Environ Microbiol. 1991;57:2928-34

82. Harrison LA, Letendre L, Kovacevich P. Purification of an antibiotic effective against Gaeumannomyces graminis var. tritici produced by a biocontrol agent, Pseudomonas aureofaciens. Soil Biol Biochem. 1993;25:215-21.

83. Duffy BK, Défago G. Zinc improves biocontrol of Fusarium crown and root rot of tomato by Pseudomonas fluorescens and represses the production of pathogen metabolites inhibitory to bacterial antibiotic biosynthesis. Phytopathology. 1997:87:1250-57.

84. Sikorski J, Stackebrandt E. Pseudomonas kilonensis sp. nov., a bacterium isolated from agricultural soil. Int J Syst Evol Microbiol. 2001;51:1549-55.

85. Stutz E, Défago G, Kern H. Naturally occurring fluorescent pseudomonads involved in suppression of black root rot of tobacco. Phytopathology. 1986;76:181.

86. Levy E, Gough FJ, Berlin KD, Guiana PW, Smith JT. Inhibition of Septoria tritic and other phytopathogenic fungi and bacteria by Pseudomonas fluorescens and its antibiotics. Plant Pathology. 1992;41:1-8.

87. Howell C, Stipanovic RD. Control of Rhizoctonia solani on cotton seedlings with Pseudomonas fluorescens and with an antibiotic produced by the bacterium. Phytopathology. 1979;69:480-2.

88. Jamali F, Sharifi-Tehrani A, Lutz MP, Maurhofer M. Influence of host plant genotype, presence of a pathogen, and coinoculation with Pseudomonas fluorescens strains on the rhizosphere expression of hydrogen cyanide- and 2,4-Diacetylphloroglucinol biosynthetic genes in P. fluorescens biocontrol strain CHAO. Microb Ecol. 2008;57:267-75.

89. Haynes W, St. Julian G, Shekleton MC, Hall HH, Tahsiro H. Preservation of infectious milky disease bacteria by lyophilization. J Insect Pathol. 1961;3:55-61.

90. Kogut M, Podoski EP. Oxidative pathways in a fluorescent Pseudomonas. Biochem J. 1953:55:800-11.

91. Bagdasarian M, Lurz R, Rückert B, Franklin F. Specific-purpose plasmid cloning vectors II. Broad host range, high copy number, RSF 1010-derived vectors, and a host-vector system for gene cloning in Pseudomonas. Gene. 1981;16:237-47.

92. Peix A, Rivas R, Mateos PF, Martínez-Molina E, Rodríguez-Barrueco C, Velázquez E. Pseudomonas rhizosphaerae sp. nov., a novel species that actively solubilizes phosphate in vitro. Int J Syst Evol Microbiol. 2003:53:2067-72.

93. Wilson M, Lindow SE. Relationship of total viable and culturable cells in epiphytic populations of Pseudomonas syringae. Appl Environ Microbiol. 1992;58:3908-13.

94. Dorn E, Hellwig M, Reineke W, Knackmuss HJ. Isolation and characterization of a 3-chlorobenzoate degrading pseudomonad. Arch Microbiol. 1974;99:61-70

95. Sørensen D, Nielsen TH, Christophersen C, Sørensen J, Gajhede M. Cyclic lipoundecapeptide amphisin from Pseudomonas sp. strain DSS73. Acta Crystallogr. 2001;57:1123-4.

96. Paternoster T, Défago G, Duffy B, Gessler C, Pertot I. Selection of a biocontrol agent based on a potential mechanism of action: degradation of nicotinic acid, a growth factor essential for Erwinia amylovora. Int Microbiol. 2010;13:195-206.

97. Skerman VBD, McGowan V, Sneath PHA. Approved lists of bacterial names. Int J Syst Bacteriol. 1980;30:225-420.

98. Schraa G, Bethe BM, van Neerven AR, Van den Tweel WJ, Van der Wende E, Zehnder AJ. Degradation 1,2-dimethylbenzene by Corynebacterium strain C125. Antonie van Leeuwenhoek. 1987;53:159-70.

99. Horvath M, Ditzelmüller GN, Loidl M, Streichsbier F. Isolation and characterization of a 2-(2,4-dichlorophenoxy) propionic acid-degrading soil bacterium. Appl Microbiol and Biotechnol. 1990;33:213-6.

100. Nagata Y, Miyauchi K, Takagi M. Complete analysis of genes and enzymes for gamma-hexachlorocyclohexane degradation in Sphingomonas paucimobilis UT26. J Ind Microbiol Biotechnol. 1999;23:380-90

101. Dyke KG, Jevons MP, Parker MT. Penicilinase production and intrinsic resistance to penicillins in Staphylococcus aureus. Lancet. 1966;1:835-8,

102. Baba T, Takeuchi F, Kuroda M, Yuzawa H, Aoki Kl, Oguchi A, et al. Genome and virulence determinants of high virulence community-acquired MRSA. Lancet. 2002;359:1819-27.

103. Kreiswirth BN, Löfdahl S, Betley MJ, O'Reilly M. The toxic shock syndrome exotoxin structural gene is not detectably transmitted by a prophage. Nature. 1983;305:709-12.

104. Christensen GD, Simpson WA, Bisno AL, Beachey EH. Adherence of slime-producing strains of Staphylococcus epidermidis to smooth surfaces. Infect Immun. 1982;37:318-26.

105. Bouchek-Mechiche K, Gardan L, Andrivon D, Normand P. Streptomyces turgidiscabies and Streptomyces reticuliscabiei: one genomic species, two pathogenic groups. Int J Syst Evol Microbiol. 2006;56:2771-6.

106. Chaston JM, Suen G, Tucker SL, Andersen AW, Bhasin A, Bode E, et al. The entomopathogenic bacterial endosymbionts Xenorhabdus and Photorhabdus: convergent lifestyles from divergent genomes. PLOS ONE. 2011;6:e27909.

\section{Submit your next manuscript to BioMed Central and take full advantage of:}

- Convenient online submission

- Thorough peer review

- No space constraints or color figure charges

- Immediate publication on acceptance

- Inclusion in PubMed, CAS, Scopus and Google Scholar

- Research which is freely available for redistribution 